\title{
Comparative Analysis between IEEE 1459 and Conservative Power Theory Through the Development of Power Meters
}

\author{
G.J. Schäffer ${ }^{1}$, F. R. Arduini ${ }^{1}$, F. A. M. Moura ${ }^{1}$, M. V. B. Mendonça ${ }^{1}$, A. J. P. R. J ${ }^{1}$, P. H. O. Rezende ${ }^{1}$ and \\ M. R. M. C. Albertini ${ }^{1}$ \\ Electrical Engineering Department, ${ }^{1}$ Universidade Federal do Triângulo Mineiro, Uberaba- Minas Gerais, Brazil \\ gabrielaschaffer3094@hotmail.com, fabricio.moura@uftm.edu.br, IEEE Member.
}

\begin{abstract}
With the undoubted growth of power electronic devices, ie, non-linear loads, there was a need for a deeper study in the power calculation, taking into account the harmonic distortions caused by these loads. Therefore, the present work aims to present, based on a test electrical system, a comparative analysis between two power theories with great discussion at present, the first one being the IEEE 1459 standard and the second the Conservative Power Theory.
\end{abstract}

\section{Key words}

Electric power, Harmonic Distortions, Electric power quality, IEEE 1459, CPT.

\section{Introduction}

In order to increase overall system efficiency and industrial automation, in recent years there has been a considerable growth of power electronics devices and microprocessors, PLCs, luminaries, among other nonlinear loads in residential, commercial and industrial electrical installations and distribution networks. These loads generate distorted currents, that is, currents with a waveform that differs from the waveform of their power supply, with high harmonic content that when injected into the electric network, provides diverse problems.

Therefore, concerns about the quality of electric energy are growing both by the electric power concessionaires and the consumers of the same, as there is a strong motivation of the concessionaires to meet the expectations of customers. Therefore, any energy problem manifested in deviations of voltage, current or frequency that results in a malfunction of the equipment, is a problem of electric power quality [1], being from visual annoyances caused by the luminous variation to the interference in electronic equipment.

Given this scenario, the study of the quality of electric power is vital for the analysis and understanding of the electrical system, in which the commercialized product is the electric energy. Therefore, it is clear that the consumer prefers a product that presents adequate parameters of quality and low cost, since there are economic impacts on public services, its customers and suppliers. In this context, there is an increase in the monitoring and analysis of the quality of electric energy, that is, worldwide searches, for the creation of norms with limits that can satisfy both the operators of the system and the consumers of the same. In this way, several researches and technical discussions arose in order to explain the power phenomena in non-sinusoidal systems. However, these methodologies must be compatible and meet the classical theory of powers in sinusoidal regime. Therefore, in 1927 were born the first formulations of power developed by Budeanu and with this triggered several other researches in the area. In order to establish a standard, to be adopted by the international scientific and productive community, the document Institute of Electrical and Electronics Engineers - IEEE 1459 was elaborated having as basic premise the decomposition of the apparent power in fundamental and not fundamental, evidencing the power derived from harmonic distortions of current and voltage [2,3].

However, the methodologies to date have some deficiencies related to the so-called non-fundamental powers. Thus, today there are several studies referring to which the best methodology to be used for calculation of electric power since there is still no convergence of opinions by scholars and regulatory agencies. Among these theories there is the Conservative Powe Theory (CPT), proposed by Tenti and Mattavelli in 2003 and updated by Tenti, Mattavelli and Paredes in 2010. It is believed that such methodology brings important innovations in electrical system applications and it allows, in terms of the behaviors and characteristics of the circuits, the detailed interpretation of the electrical systems [4].

In this context, this work presents a comparative analysis of the methodology used by IEEE 1459 and the Conservative Powe Theory (CPT) for the quantification of powers in non-sinusoidal systems, in order to illustrate to the reader the main modifications of the proposed new methodology. For the purpose of developing the discussions, this paper is structured as follows: the power theories that will be used are presented in section 2 . In section 3, demonstrate the test system used in this work. In section 4, the studies are presented through the electrical system used together with the comparisons between the proposed theories. In section 5, the main conclusions about the problems studied are presented. 


\section{Power Theories}

The main theories of powers under non-sinusoidal, globally recognized conditions have been proposed in the time domain such as the Czarnecki and Depenbrock theories, as well as in the frequency domain, such as the Budeanu and Emanuel theories which are currently used by the IEEE. And later, a new approach to Conservative Power Theory, which is used, as well as the proposed theories in the domain of time, the current decomposition. Among these, the theory in the field of frequency, IEEE 1459 of Emanuel and the last approach, CPT, which present a possibility of expression of the powers in an electric system with harmonic distortions, will be highlighted.

\section{1- IEEE 1459 Method}

Alexander Emanuel, president of the IEEE non-sinusoidal case studies group, proposed a power decomposition similar to that of Budeanu which is divided into active, reactive and distorting power. However, this decomposition differs in the way of obtaining the powers, which in this case is the separation of the fundamental component of the harmonic components of voltage and current as shown below.

$$
\begin{gathered}
V^{2}=V_{1}^{2}+\sum_{h \neq 1} V_{h}^{2}=V_{1}^{2}+V_{H}^{2} \\
I^{2}=I_{1}^{2}+\sum_{h \neq 1} I_{h}^{2}=I_{1}^{2}+I_{H}^{2}
\end{gathered}
$$

Where index 1 represents the fundamental components and the index $h$, the harmonics. It is noticed that Alexander makes a sum of the square of the harmonic components of voltage and current, generating the apparent power from (1) and (2):

$$
\begin{gathered}
S^{2}=V^{2} I^{2}=\left(V_{1}^{2}+V_{H}^{2}\right) *\left(I_{1}^{2}+I_{H}^{2}\right) \\
=\left(V_{1} I_{1}\right)^{2}+\left(V_{1} I_{H}\right)^{2} \\
+\left(V_{H} I_{1}\right)^{2}+\left(V_{H} I_{H}\right)^{2} \\
=S_{1}^{2}+D_{I}^{2}+D_{V}^{2}+S_{H}^{2} \\
\begin{aligned}
& S_{H}=\left(V_{H} I_{H}\right)= S_{1} \frac{V_{H} I_{H}}{V_{1} I_{1}} \\
&=S_{1}\left(T H D_{V}\right)\left(T H D_{I}\right) \\
& P_{H}=\sum_{h \neq 1} P_{h}=\sum_{h \neq 1} V_{h} I_{h} \cos \theta_{h}
\end{aligned}
\end{gathered}
$$

Where $S_{1}$ is the fundamental apparent power, $D_{I}$ the current distortion power, $D_{V}$ the voltage distortion power, $S_{H}$ the harmonic apparent power and $P_{H}$ the active harmonic power wich, according to the author, is indicative harmonic pollution in the load. It must be remembered that the achievement of the fundamental powers is identical to the classical method, and it is not necessary to present them. In addition, the author relates the fundamental reactive power as needed to improve the power factor.

Thus, the non-fundamental apparent power was defined $\mathrm{S}_{\mathrm{N}}$ which according to Alexander, would be a good estimate of the size of the harmonic compensator [3].

$$
S_{N}=\sqrt{D_{I}^{2}+D_{V}^{2}+S_{H}^{2}}
$$

The amount of power related to voltage and current distortions is given by the distortion equations described in (7) and (8).

$$
\begin{aligned}
& D_{\mathrm{V}}=\left(\mathrm{V}_{\mathrm{H}} \mathrm{I}_{1}\right)=\mathrm{I}_{1} \sqrt{\sum_{\mathrm{h} \neq 1} \mathrm{~V}_{\mathrm{h}}^{2}} \\
& \mathrm{D}_{\mathrm{I}}=\left(\mathrm{V}_{1} \mathrm{I}_{\mathrm{H}}\right)=\mathrm{V}_{1} \sqrt{\sum_{\mathrm{h} \neq 1} \mathrm{I}_{\mathrm{h}}^{2}}
\end{aligned}
$$

The power factor also separates the fundamental component. Thus, we have the real power factor and the displacement power factor, which are presented, respectively, by equations (9) and (10).

$$
\begin{gathered}
\mathrm{fp}=\frac{\mathrm{P}}{\mathrm{S}} \\
\mathrm{fp}_{1}=\frac{\mathrm{P}_{1}}{\mathrm{~S}_{1}}
\end{gathered}
$$

Notably, the calculation of the power factor does not directly include the reactive component, only active and apparent power. Although there is a controversial part of this formulation, which refers to the reactive and distorting powers over its physical interpretations and definitions for total distortion power, this method was adopted by the IEEE 1459 standard in 2010.

\section{2- Method of Conservative Power Theory}

In this theory, all mathematical foundations follow the assumption of periodic functioning that are applied to the analysis of electrical circuits, the terms of power and energy are defined in instantaneous and average terms. In addition, current decomposition is made from the definitions of active power and reactive energy, taking into account voltage and current distortions. Next, the apparent, reactive and residual power is defined. The reference used throughout the theory is presented in 2010 by Paredes and Mattavelli, described in [4,5].

First, it is assumed that all quantities involved in the analysis are periodic in nature, thus considering $\mathrm{T}$ the period, the fundamental frequency being the inverse of the period and the angular frequency as $\boldsymbol{\omega}=\mathbf{2} \boldsymbol{\pi} \boldsymbol{f}$, here are the operators: The average value of a quantity $\mathrm{x}_{(\mathrm{t})}$ and its Euclidian norm defined as $\vec{x}$ e $\|x\|$. X being the effective 
value of x., And the internal product of two periodic quantities as $\langle\boldsymbol{x}, \boldsymbol{y}\rangle$.

Then, if the internal product of these quantities results in a value equal to zero, the quantities are said to be orthogonal, and this orthogonalised serves for sinusoidal functions displaced by 90 degrees or for harmonic components of different orders. This concept of orthogonality was demonstrated in Fryze's theory [6]. Thus, the inequality for the domestic product now proposed by Cauchy-Schwartz is defined as:

$$
\langle x, y\rangle \leq\|x\|\|y\|=X Y
$$

Another important property is the unbiased integral considering $\mathrm{x}_{(\mathrm{t})}$ with its mean null value, represented in (12), its integral in time and unbiased will be represented in (13) and (14), respectively.

$$
\begin{aligned}
& \bar{x}=\frac{1}{T} \int_{0}^{T} x(t) \mathrm{dt}=0 \\
& x_{\int}(\mathrm{t})=\int_{0}^{t} x(\tau) \mathrm{d} \tau \\
& \hat{x}(\mathrm{t})=x_{\int}(t)-\bar{x}
\end{aligned}
$$

Where $\vec{x}$ is an average value and the term described as unbiased the average value is disregarded.

Thus, according to Tellegen's Theorem, the scalar product of the terms $u_{l}, \widehat{u_{l}}, \breve{u}_{l}$, as well as the terms of the current, consist of Kirchoff's laws. In this way, the primordial conservative quantities for this theory, for a polyphase network, considering $\mathrm{u}$ and $\mathrm{i}$ as vectors of voltage and current have collective instantaneous power, reactive energy collective snapshot and respectively their average values:

$$
\begin{aligned}
& P=\bar{p}=\langle\underline{u}, \underline{i}\rangle=\frac{1}{T} \int_{0}^{T} \underline{u} \cdot \underline{i} d t \\
&=\frac{1}{T} \sum_{\mu=1}^{m} \int_{0}^{T} u_{\mu}(t) \cdot i_{\mu}(t) \\
&=\sum_{\mu=1}^{m} P_{\mu} \\
& W=\bar{w}=\langle\underline{\hat{u}}, \underline{i}\rangle \\
&=\frac{1}{T} \sum_{\mu=1}^{m} \int_{0}^{T} \widehat{u_{\mu}}(t) \cdot i_{\mu}(t) d t=\sum_{\mu=1}^{m} W_{r \mu}
\end{aligned}
$$

Being, $\mathrm{P}$ e $\mathrm{P} \mu$ mean values, in sinusoidal or nonsinusoidal condition, the phase quantities represent the active power which represents the permanent flow of energy per unit time through the network cut, and knowing that $\mathrm{P}$ is independent of the voltage and is a conservative component, it is additive over all components of the network. The oscillations of power and flows of currents in the network caused by energy storage elements must be taken into account and are represented for sinusoidal condition by the reactive power $\mathrm{Q}$. However, for non-sinusoidal situations, this theory introduces a new term called energy reactive, since the concept of reactive power has not yet been realized.

$$
Q=\omega W_{r}=V I \sin \varphi
$$

Thus, the conservative term given for both active power and reactive energy means that energy is conserved, or rather, the energy entering a given circuit is the same as that which comes out of it.

Furthermore, this theory makes the use of active and reactive current decompositions, but with an additional component, the residual or zero current.

The active current is defined as the minimum required to provide active power and is expressed by the equation below:

$$
i_{a}=\frac{\langle v, i\rangle}{\|v\|^{2}} v=\frac{P}{V^{2}} v
$$

The reactive current is defined as the minimum required to supply reactive energy $\mathrm{Wn}$, this is related to the phase shift between voltage and current, whether caused by the presence of energy storage elements or by the presence of current-deflecting electronic circuits. Thus, it is expressed by the equation below:

$$
i_{r}=\frac{\langle\hat{v}, \mathrm{i}\rangle}{\|\hat{v}\|^{2}} \hat{v}=\frac{W_{r}}{\hat{V}^{2}} \hat{v}
$$

The reactive current carries all reactive energy and no active power, since both reactivity and equivalent capacitance do not produce active power, and yet, the reactive energy is proportional to the difference between the average total inductive energy and the total average capacitive energy, ie is, one compensates the other, so to represent the reactive energy, it will use only the equivalent reactivity.

The residual current does not carry active power or reactive energy, that is, the internal product of $P_{v}=\left\langle v, i_{v}\right\rangle$ and $W_{r v}=\left\langle\hat{v}, i_{v}\right\rangle$ should result in zero, and it can be defined by the equation below:

$$
i_{v}=i-i_{a}-i_{r}
$$

Its interpretation is best seen through frequency domain, Fourier series decomposition, explicitly expressed in reference [5]. Thus, the terms belonging to residual current can be defined as dispersed active current $\left(i_{a s}\right)$, dispersive reactive current $\left(i_{r s}\right)$ and current generated by the load $\left(i_{g}\right)$, resulting in the total current as:

$$
i=i_{a}+i_{r}+i_{a s}+i_{r s}+i_{g}
$$


It is known that voltage and current effective values directly influence the power of the supply source, so this power is characterized by the product of the current and voltage efficacy values and is able to supply and is defined as apparent power, which can be broken down into the following expressions:

$$
\begin{array}{r}
A^{2}=V^{2} I^{2}=V^{2} I_{a}^{2}+V^{2} I_{r}^{2}+V^{2} I_{a s}^{2} \\
+V^{2} I_{r s}^{2}+V^{2} I_{g}^{2} \\
A^{2}=P^{2}+Q^{2}+D_{a}^{2}+D_{r}^{2}+D_{g}^{2} \\
=P^{2}+Q^{2}+D^{2}
\end{array}
$$

Where $\mathrm{A}$ is apparent power [VA], $\mathrm{P}$ at active power [W], $\mathrm{Q}$ at reactive power [VAr], D at residual power [VA] which is composed of dispersed active power (Da), dispersed reactive power ) and generated harmonic power (Dg).

The power factor, shown below, can also be composed, respectively, by the nonlinearity factor $\left(\lambda_{D}\right)$ and the reactivity factor $\left(\lambda_{Q}\right)$, shown below.

$$
\begin{gathered}
\lambda=\frac{P}{\sqrt{P^{2}+Q^{2}+D^{2}}} \\
\lambda_{D}=\frac{D}{\sqrt{P^{2}+Q^{2}+D^{2}}} \\
\lambda_{Q}=\frac{Q}{\sqrt{P^{2}+Q^{2}}}
\end{gathered}
$$

Thus, it is possible, through the power factor, to evaluate the effects of non-active powers in a non-sinusoidal system.

Notably, the two theories in question have not only different nomenclatures but different methodologies, especially with respect to reactive power, and the great criticism of the methodology of Emanuel and Budeanu is the sum of the contributions of the harmonic components, but today it is known that there are harmonics in different phases. The CPT method calculates the reactive power according to the stored reactive energy, which has different signals if the characteristic of the component is inductive or capacitive. Differentiating from the formulation presented above.

\section{Computational Modeling}

In order to perform a comparative analysis between the theory proposed by IEEE 1459 and CPT, two power meters were developed, based on the theories in question, using the ATPDraw computational software, figure 1 .

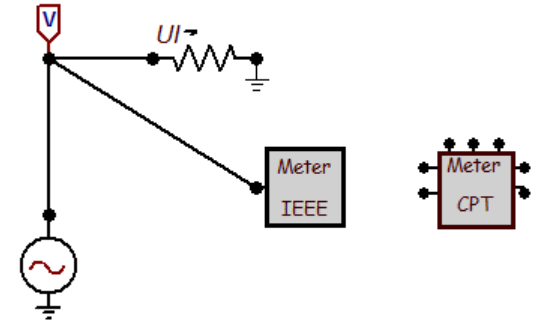

\section{1- IEEE 1459 Power Meter}

The IEEE 1459 power meter was developed using the MODELS computational language of the ATPDraw software, according to the equations presented in section 2.1. To use it, you must insert the harmonic components of voltage, voltage angle, current and current angle as shown in the figure 2.

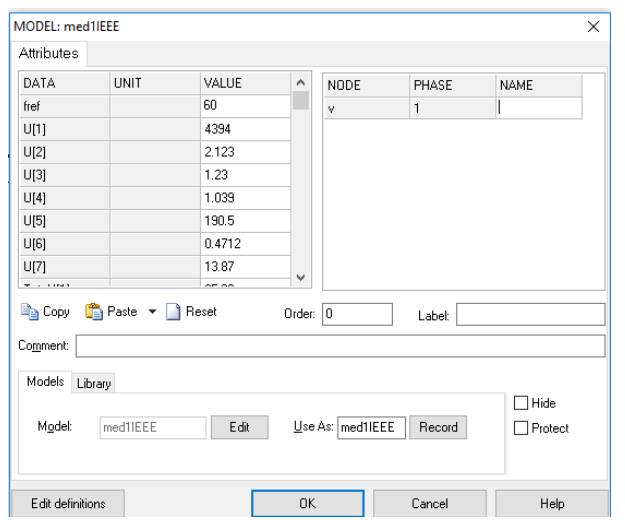

Fig. 2- IEEE 1459 Computational Interface.

For the power calculations, which consider the voltage or current amplitudes of each harmonic order, it was considered up to the 25 th harmonic order, a rule required by Module 8 of the Distribution Procedures - PRODIST, [9]. However, this platform allows a retrograde number of variables to be inserted, so it was considered up to the 7th harmonic order.

\section{2- CPT Power Meter}

The CPT power meter, also developed in the ATPDraw software, used the TACS tool to perform equations and current decomposition, and used the MODELS tool to calculate mean values.

This meter, shown in figure 1 , does not have the need of insertion of harmonic components, since it is connected in the circuit itself and has as input variables the phase voltage and phase current.

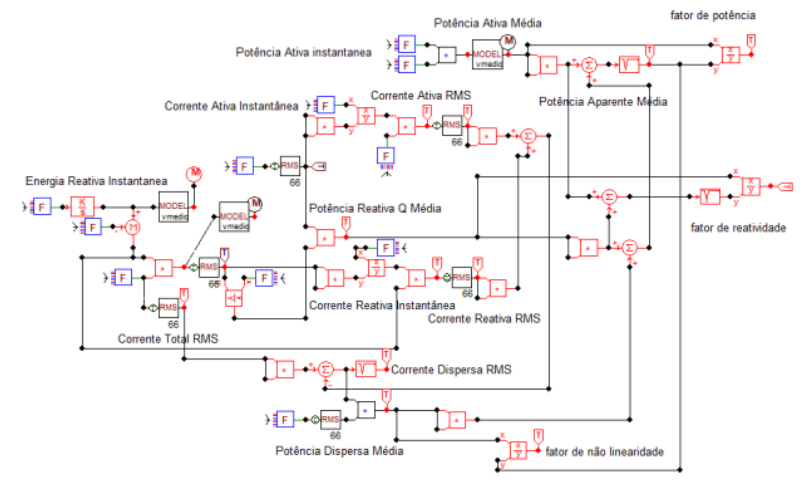

Fig. 3- CPT Power Meter.

It is worth mentioning that the data to be obtained by the power meters are monophasic, therefore phase-neutral.

Fig. 1- Power Meters: IEEE 1459 and CPT. 


\section{Case Study}

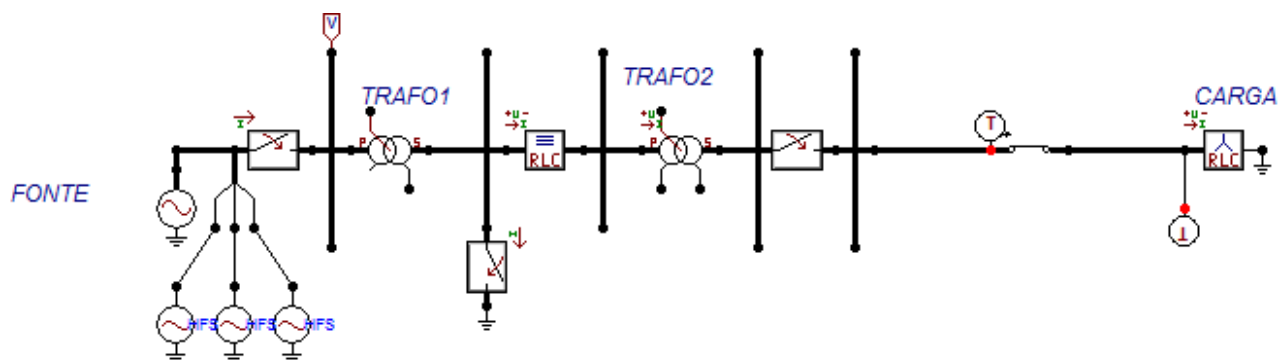

Figure 4- Electrical Test System

In order to validate the developed program, a electrical test system, shown in figure 4 , was used.The circuit has a threephase source of $13.8 \mathrm{kV}$ operating at $60 \mathrm{~Hz}$ and the circuit data are pointed out in Tables 1,2,3 and 4 .

A laboratory structure for experimental analysis of the theory is under development and the results will be published later.

Table 1- Transformers data

\begin{tabular}{c|c|c} 
& T1 & T2 \\
\hline Rated Power & $5 \mathrm{MVA}$ & $5 \mathrm{MVA}$ \\
\hline Primary Voltage & $13.8 \mathrm{kV}$ & $69 \mathrm{kV}$ \\
\hline Secondary Voltage & $69 \mathrm{kV}$ & $0.38 \mathrm{kV}$ \\
\hline $\begin{array}{c}\text { Percentage } \\
\text { Resistance }\end{array}$ & $1.12 \%$ & $2 \%$ \\
\hline $\begin{array}{c}\text { Percent } \\
\text { Impedance }\end{array}$ & $3 \%$ & $5 \%$ \\
\hline Connection & Delta-Ground Star & $\begin{array}{c}\text { Ground Star - } \\
\text { Ground Star }\end{array}$
\end{tabular}

Table 2- Transmission lines data.

\begin{tabular}{c|c|c} 
Line & Resistance $\boldsymbol{\Omega} /$ fase) & Reactance $(\boldsymbol{\Omega} /$ fase $)$ \\
\hline RL & 1.059 & 0.0209
\end{tabular}

Table 3- Load data.

\begin{tabular}{c|c|c|c} 
Load & Voltage & Rated Power & Power Factor \\
\hline $\begin{array}{c}\text { Linear } \\
\text { Load }\end{array}$ & $380 \mathrm{~V}$ & $3 \mathrm{MVA}$ & 0,92
\end{tabular}

\section{1- Case I}

In this case, the supply voltage is purely sinusoidal and there are no non-linear loads, that is, without the current sources and harmonic voltages.

Analyzing only phase A for all cases, Table 4 presents the current, voltage, and current values:

Table 4- Operation Condition I.

\begin{tabular}{c|c|c}
$\begin{array}{c}\text { Harmonic } \\
\text { Order }\end{array}$ & Voltage [V] & Current [A] \\
\hline $1^{\mathrm{a}}$ & $211.6\left\llcorner 58.18^{\mathrm{o}}\right.$ & $4394\left\llcorner 35.08^{\mathrm{o}}\right.$ \\
\hline $3^{\mathrm{a}}$ & $0.038\left\llcorner 28.48^{\mathrm{o}}\right.$ & $1.109\left\llcorner 13.45^{\mathrm{o}}\right.$ \\
\hline $5^{\mathrm{a}}$ & $0.019\left\llcorner 18.36^{\circ}\right.$ & $0.6059\left\llcorner 8.52^{\circ}\right.$ \\
\hline $7^{\mathrm{a}}$ & $0.013\left\llcorner 13.71^{\circ}\right.$ & $0.4221\left\llcorner 6.48^{\circ}\right.$ \\
\hline $9^{\mathrm{a}}$ & $0.01\left\llcorner 11.14^{\mathrm{o}}\right.$ & $0.325\left\llcorner 5.44^{\circ}\right.$ \\
\hline $11^{\mathrm{a}}$ & $0.008\left\llcorner 9.56^{\circ}\right.$ & $0.2646\left\llcorner 4.86^{\circ}\right.$
\end{tabular}

Table 5- IEEE 1459 Meter for Case I

\begin{tabular}{c|c|c|c}
$\boldsymbol{S}$ & \multicolumn{2}{|c|}{$\boldsymbol{P}$} & $\boldsymbol{N}$ \\
\hline $929.77 \mathrm{kVA}$ & \multicolumn{2}{|c|}{$855.22 \mathrm{~kW}$} & $364.78 \mathrm{kVA}$ \\
\hline $\boldsymbol{S}_{\boldsymbol{1}}$ & \multicolumn{2}{|c|}{$\boldsymbol{P}_{\mathbf{1}}$} & $\boldsymbol{Q}_{\mathbf{1}}$ \\
\hline $\mathrm{kVA}$ & \multicolumn{2}{|c|}{$855.22 \mathrm{~kW}$} & $364.78 \mathrm{kVAr}$ \\
\hline $\boldsymbol{S}_{\boldsymbol{N}}$ & $\boldsymbol{S}_{\boldsymbol{H}}$ & $\boldsymbol{P}_{\boldsymbol{H}}$ & $\mathbf{Q}$ \\
\hline $0.6875 \mathrm{kVA}$ & $0.2438 \mathrm{VA}$ & $0.2209 \mathrm{~W}$ & $364.78 \mathrm{kVAr}$ \\
\hline $\mathbf{F p}$ & $\mathbf{f p 1}$ & $\boldsymbol{D}_{\boldsymbol{i}}$ & $\boldsymbol{D}_{\boldsymbol{v}}$ \\
\hline 0.91982 & 0.91982 & $550.46 \mathrm{VA}$ & $411.82 \mathrm{VA}$
\end{tabular}

Table 6- CPT Meter for Case I

\begin{tabular}{c|c|c|c}
$\boldsymbol{A}$ & $\boldsymbol{P}$ & $\boldsymbol{D}$ & $\mathbf{Q}$ \\
\hline $929.9 \mathrm{kVA}$ & $855.19 \mathrm{~kW}$ & $20.04 \mathrm{kVA}$ & $364.8 \mathrm{kVAr}$ \\
\hline $\boldsymbol{\lambda}$ & $\boldsymbol{\lambda}_{\boldsymbol{D}}$ & $\lambda_{Q}$ & $\boldsymbol{W r}$ \\
\hline 0.9196 & 0.02155 & 0.3924 & $967.73 \mathrm{VAr}$
\end{tabular}

\section{2- Case II}

In this case, the supply voltage is not purely sinusoidal, that is, there is a source of harmonic voltage shown in Table 7 .

Table 7- Data Harmonic Voltage Source.

\begin{tabular}{c|c|c|c} 
Source & $\begin{array}{c}\text { 5th Harmonic } \\
\text { Order [A] }\end{array}$ & $\begin{array}{c}\text { 7th Harmonic } \\
\text { Order [A] }\end{array}$ & $\begin{array}{c}\text { 11th Harmonic } \\
\text { Order [A] }\end{array}$ \\
\hline F1 & $796.7432\left\llcorner-17.65^{\circ}\right.$ & $79.6743\left\llcorner 26.85^{\circ}\right.$ & $7.9674\left\llcorner 148.1^{\circ}\right.$
\end{tabular}

Analyzing only phase A for all cases, Table 8 presents the current, voltage, and current values:

Table 8- Condition of Operation II.

\begin{tabular}{c|c|c}
$\begin{array}{c}\text { Harmonic } \\
\text { Order }\end{array}$ & Voltage [V] & Current [A] \\
\hline $1^{\mathrm{a}}$ & $211.6\left\llcorner 58.18^{\mathrm{o}}\right.$ & $4394\left\llcorner 35.08^{\mathrm{o}}\right.$ \\
\hline $3^{\mathrm{a}}$ & $0.04357\left\llcorner 58.63^{\circ}\right.$ & $1.23\left\llcorner 23.33^{\circ}\right.$ \\
\hline $5^{\mathrm{a}}$ & $19.92\left\llcorner-43.53^{\circ}\right.$ & $190.5\left\llcorner-108.3^{\mathrm{o}}\right.$ \\
\hline $7^{\mathrm{a}}$ & $1.984\left\llcorner-92.81^{\circ}\right.$ & $13.87\left\llcorner-164.4^{\mathrm{o}}\right.$ \\
\hline $9^{\mathrm{a}}$ & $0.0199\left\llcorner-16.64^{\circ}\right.$ & $0.2643\left\llcorner-8.535^{\circ}\right.$ \\
\hline $11^{\mathrm{a}}$ & $8.388\left\llcorner-149.9^{\circ}\right.$ & $39.33\left\llcorner 131.9^{\circ}\right.$
\end{tabular}

Thus, by applying the meters shown in Fig 1, the following power outputs were obtained at the coupling point, i.e., in the load. 
Table 9- IEEE 1459 Meter for Case II

\begin{tabular}{c|c|c|c}
$\boldsymbol{S}$ & \multicolumn{2}{|c|}{$\boldsymbol{P}$} & $\boldsymbol{N}$ \\
\hline $934.8 \mathrm{kVA}$ & \multicolumn{2}{|c|}{$856.85 \mathrm{~kW}$} & $373.72 \mathrm{kVA}$ \\
\hline $\boldsymbol{S}_{\mathbf{1}}$ & \multicolumn{2}{|c|}{$\boldsymbol{P}_{\mathbf{1}}$} & $\boldsymbol{Q}_{\boldsymbol{1}}$ \\
\hline $\mathrm{kVA}$ & \multicolumn{2}{|c|}{$855.22 \mathrm{~kW}$} & $364.78 \mathrm{kVAr}$ \\
\hline $\boldsymbol{S}_{\boldsymbol{N}}$ & $\boldsymbol{S}_{\boldsymbol{H}}$ & $\boldsymbol{P}_{\boldsymbol{H}}$ & $\mathbf{Q}$ \\
\hline $96.881 \mathrm{kVA}$ & $3.824 \mathrm{kVA}$ & $1.627 \mathrm{~kW}$ & $368.24 \mathrm{kVAr}$ \\
\hline $\mathbf{f p}$ & $\mathbf{f p 1}$ & $\boldsymbol{D}_{\boldsymbol{i}}$ & $\boldsymbol{D}_{\boldsymbol{v}}$ \\
\hline 0.91661 & 0.91982 & $40.421 \mathrm{kVA}$ & $87.963 \mathrm{kVA}$
\end{tabular}

\begin{tabular}{c|c|c|c}
\multicolumn{4}{|c}{ Table 10- CPT Meter for Case II } \\
$\boldsymbol{A}$ & $\boldsymbol{P}$ & $\boldsymbol{D}$ & $\mathbf{Q}$ \\
\hline $935 \mathrm{kVA}$ & $856.81 \mathrm{~kW}$ & $73.368 \mathrm{kVA}$ & $367.06 \mathrm{kVAr}$ \\
\hline $\boldsymbol{\lambda}$ & $\boldsymbol{\lambda}_{\boldsymbol{D}}$ & $\boldsymbol{\lambda}_{\boldsymbol{Q}}$ & $\boldsymbol{W r}$ \\
\hline 0.91637 & 0.078469 & 0.39379 & $969.57 \mathrm{VAr}$
\end{tabular}

Observing the tables above, we can see the proximity of the power and power factor values, in both cases, closer in case I. However in Case II there is a greater difference in the nonfundamental power $\mathrm{Q}$.

The results suggest that CPT seems to be a very interesting alternative to the analysis, control and regulation of different power circuits, from the case of traditional sinusoidal and balanced voltage and current signals to non-linear load circuits with deteriorated voltages. [10]

\section{Conclusion}

It is noticed that there is a great reciprocity in the work domains, as for example, the theory proposed by the IEEE 1459 is based on the Budeanu theory and the theory of the conservative power has traces of the theory of Fryze and Czarnecki. In addition, the presence of fundamental, harmonic, active and non-active currents is considered in both time and frequency domain.

There are divergences between the theories, since they were created based on their implementations, that is, while some are geared toward tariffs, others are focused on compensator and energy compensation projects, so-called instantaneous power theories, which are not suitable for monitoring the quality of energy [6].

Another major difference is the naming and naming of the same physical or mathematical meanings.

The theory of conservative power, which has been detailed, has its definitions part in the time domain and part can be expressed in the frequency domain. This theory, still recent in the study scenario, already has some deficiencies, as well as others. This, based on Fryze, repeated errors, such as not explaining the physical meaning of the reactive current and reactive energy, which is not considered a physical quantity [8].

The CPT, as previously seen, has the concept of the orthogonality between the voltage and the current. In addition, the physical and mathematical background presents the same process of active power. Therefore, reactive power refers to the reactive energy, which takes into account the stored energy in the inductor and capacitor. With this, the net energy of the circuit is taken, using the concept that the stored energy in the inductor is opposite to the energy of the capacitor. Thus, the reactive power is not conservative for systems whose frequency varies and has voltage distortions, unlike the theory proposed by Budeanu and Emannuel that add up all the harmonic components, not considering the inductive and capacitive characteristics of each order.

Thus, although a unified approach to power theories, which is error free, can be implemented in both energy and energy metering and charging, much study is still needed on the basis of errors found between various theories.

\section{References}

[1] Dugan, R. C., Mc Granaghan, M. F., Electrical power system quality. Segunda Edição. Editora McGraw-Hill, Estados Unidos da América, 2002.

[2]Lima, Ezequiel J. Reflexões sobre as teorias de potência elétrica em regime não senoidal. Dissertação de mestrado para obtenção do título de mestre em Engenharia Elétrica Universidade Federal de Uberlândia. Uberlândia, 2014.

[3]Modesto, S. Avaliação Computacional de Métodos de Obtenção da Potência Elétrica para Tensões e Correntes Equilibradas e Desequilibradas com Distorções Harmônicas. Universidade Federal do Triângulo Mineiro. Uberaba, 2015.

[4] Fraissat, F.B. Estudo da Teoria da Potência Conservativa para Análise de Sistemas Elétricos. Dissertação de mestrado para obtenção do título de mestre em Engenharia Elétrica Universidade Estadual Paulista. Bauru, 2011.

[5] Paredes, H. K. M. Teoria da Potência Conservativa: Uma nova Abordagem para o Controle Cooperativo de Condicionadores de Energia e Considerações sobre Atribuição de Responsabilidades. Dissertação de mestrado para obtenção do grau de doutor em Engenharia Elétrica. Faculdade de Engenharia Elétrica e de Computação, Universidade Estadual de Campinas, 2011.

[6] Deckmann, S.M.; Pomilio J. A. Condicionamento de Energia Elétrica e Dispositivos FACTS. LCEE-DSCE-FEEC-UNICAMP, Campinas, 2009.

[7] L.S. Czarnecki, "Considerations on the Reactive Power in Nonsinusoidal Situations," IEEE Transaction on Instrumentation and Measurement, vol. IM-34, no. 3, pp. 399-404, September 1985.

[8] Czarnecki, L.S." What is wrong with the Conservative Power Theory (CPT)". IEEE Transactions on Instrumentation and Measurement, 2016.

[9] L.S. Czarnecki, "Considerations on the Reactive Power in Nonsinusoidal Situations," IEEE Transaction on Instrumentation and Measurement, vol. IM-34, no. 3, pp. 399-404, September 1985.

[10] PRODIST - Procedures for Electricity Distribution in the National Electric System, Module 8, Quality of Electricity, 2012. Available at: http://www.aneel.gov.br/modulo-8. Accessed in Setember 30, 2016. \{In Portuguese \}

[11] Paredes, H. K. M. et al.. "A Comparative Analysis of FBD,PQ and CPT Current Decompositions-Part I:Three-Phase Three-Wire Systems". IEEE Bucharest Power Tech Conference, June 28th - July 2nd, Bucharest, Romania, 2009.

[12] Vasconcellos, A. B. et al. «Applications of Tuned Passive Harmonic Filters in a Busbar With Non-linear Loads". IEEE Transactions on Instrumentation and Measurement, 2012.

[13] ANEEL National Electric Energy Agency (2013). Normative Resolution $\mathrm{n}^{\circ}$ 482. Accessed in June 10, 2017, in http://www.aneel.gov.br/area.cfm?idArea=757\&idPerfil=2. $\{$ In Portuguese\}.

[14] Marafão, F. et al. "Possible Shunt Compensation Strategies Based on Conservative Power Theory". International School on Nonsinusoidal Currents and Compensation. Lagow, Poland. June, 2010 . 